\title{
Effect of Footwork Training on Some physical Capabilities and Species of shooting in Basketball Players under 15 years old the Stateof Kuwait
}

\author{
Abdullah Mohammed Ali \\ The Ministry of Education
}

\section{Introduction:-}

Basketball is one of the most popular teams based sports played and watched throughout the world. It is the fastest-growing sport in the worldfor many reasons. Basketball is a team game, individual execution of fundamental skills is essential for team success [4].

Basketball is an extremely dynamic sport that requires movements in multiple planes of motion as well as rapid transitions from jogging to sprinting to jumping [5], [10].

Increasing interest in basketball in the world requires fromspecialists to continuously discover new means and methods in working with basketball players. The complexity and sensitivity of training of basketball players are undeniable; hence, the scientific and professional approaches are very important in developing the process and controlling the effects of training [6].

Footwork is of utmost importance in all sports, but particularly in the game of Basketball, It is recommended that players execute footwork as follows; Maintain a balanced position, Move along straight lines whenever possible, Change directions sharply, Execute combinations of footwork patterns and fakes with and without ball. [8]When introducing players to the fundamentals of footwork, start without the ball, it distracts begin nine players and should only be 
introduced when players can correctly perform fundamentals without the ball. [8], [11]

The importance of footwork is obvious. The footwork develops foot speed, control, landing coordination, balance, and forward and backward movement, all of which make a better player on the court. The sport of basketball requires many changes in direction, quick movements and Explosive jumping, to ensure the players can perform these skills properly and handle the stresses that come with the sport, footwork training will be an important training component to include in the trainingregimen.]3[,]5[

Good footwork allows the players to get space for their shot. Good footwork and agility enhances every aspect of a basketball player's skills. It is the foundation of his entire game.

Footwork can enhance player's ability to play offense of the game of basketball, all fundamental skills in basketball namely shooting, rebounding movements need a sound foot work to achieve high level performance; Studies have proved that the ability to use the proper foot work has the greater impact moving in to different offensive positions. [4]

He importance of footwork and agility is underestimated today. The top teams focus on valuable practice time to developing their player's quality of footwork, balance and agility. Every basketball player loves to practice dribbling, going to the basket, shooting the ball and in the past the majority of practice time, both as a team and individually, was spend on these areas. Now we understand that good agility and footwork allows all the other areas of the game to be successful. 


\section{Objectives:-}

Learning about the Effect of Footwork Training on some physical Capabilities and Species of shooting in Basketball Players under 15 years old the State of Kuwait, By achieving the following duties:-

(1) Learning about the effect of Footwork Training on the level of on some physical Capabilities in Basketball Players under 15 years old.

(2) Learning about the effect of Footwork Training on the level of on Species of shooting in Basketball Players under 15 years old.

\section{Hypothesis:-}

(1) There are statistically significant differences between Measure before and after the experiment in the level of some physical Capabilities and in favor of measurement after.

(2) There are statistically significant differences between Measure before and after the experiment in the level of Species of shooting and in favor of measurement after.

Key words: Footwork, physical, shooting

\section{Methods:- Approach:-}

The study based on an experimental approach for Unit group usingmeasurement before and after applying a Footwork Training

\section{Sample:- Core sample:-}

The study targeted a sample from Players under 15 years old, From the Yarmouk Sports Club, and the total number (17) Player and they weredeliberately chosen, 2019/2020 season.

\section{Exploratory sample:-}

It was selected (16) players from the basketball team under 15 years old of Arabic Sports Club, to conduct exploratory study.

The researcher also homogeneity of the sample of the research as a 
whole, (17) players to make sure they fall under the normal curve in the variables (age -length - weight - Old training), as shown in Table (1), The researcher also found a homogeneity of the sample of researcher in the also physical variables and Species of shooting of the members of the research sample, as illustrated in Table (2), (3).

Table (1)

Statistical characterization of the sample individuals in the variables"Age - Height - Weight - old training"

$\mathbf{N}=\mathbf{1 7}$

\begin{tabular}{|c|c|c|c|c|}
\hline Variables & $\begin{array}{l}\text { measuring } \\
\text { unit }\end{array}$ & means & $\begin{array}{c}\text { Std Deviation } \\
\end{array}$ & skew \\
\hline Age & Year & 14.205 & 0.201 & 0.118 \\
\hline Height & C.m & 171.904 & 6.329 & 0.376 \\
\hline weight & K.g & 62.084 & 5.738 & 0.681 \\
\hline Old training & Year & 1.904 & 0.897 & 1.093 \\
\hline
\end{tabular}

Table (1) shows the homogeneity of the individuals in the research sample in the variables " age - height - weight - Old training ", since the values of the torsion coefficients of these variables are limited to $( \pm 3)$, which means that the distribution of the individuals of the research sample in these variables is moderate.

Table (2)

Statistical characterization of sample in the physical tests

\begin{tabular}{|c|c|c|c|}
\hline Variables & \begin{tabular}{l|l}
$\begin{array}{l}\text { measuring } \\
\text { unit }\end{array}$ & means \\
\end{tabular} & Std Deviation & skew \\
\hline $\begin{array}{l}\text { Plank MuscleStrength } \\
\text { Test }\end{array}$ & Sec 37.254 & 6.542 & 0.781 \\
\hline 28m sprint test & Sec5.791 & 0.315 & 0.290 \\
\hline $\begin{array}{l}28 \mathrm{~m} \text { sprint } \\
\text { dribbling test }\end{array}$ & Sec6.564 & 0.473 & 0.114 \\
\hline Nelson Reaction test & Sec 2.436 & 0.214 & 0.089 \\
\hline $\begin{array}{c}10 \times 5 \mathrm{~m} \text { shuttle run } \\
\text { Test }\end{array}$ & Sec7.994 & 0.498 & 0.428 \\
\hline T drill test & Sec 10.143 & 0.803 & 0.327 \\
\hline orientation SR test & Sec 14.903 & 3.265 & 0.968 \\
\hline stork stand test & point 45.092 & 7.434 & 0.794 \\
\hline s- sit and reach test & C.m6.524 & 3.092 & 1.656 \\
\hline
\end{tabular}


Table (2) shows the homogeneity of the research sample in physicaltests, as the skew of research sample are between $( \pm 3)$ in the variables.

Table (3)

Statistical characterization of sample in Species of shooting tests $\mathrm{N}=17$

\begin{tabular}{l|c|l|c|l}
\hline Variables & $\begin{array}{l}\text { measuring } \\
\text { unit }\end{array}$ & means & Std Deviation & skew \\
\hline $\begin{array}{l}\text { Two-point shooting } \\
\text { test }\end{array}$ & point & 4.546 & 0.471 & 0.886 \\
$\begin{array}{l}\text { Two-point jump } \\
\text { shooting test }\end{array}$ & point & 4.215 & 0.683 & 0.904 \\
$\begin{array}{l}\text { Three-point } \\
\text { shooting test }\end{array}$ & point & 3.200 & 0.554 & 0.628 \\
\hline \hline
\end{tabular}

Table (2) shows the homogeneity of the research sample in Species of shooting tests, as the skew of research sample are between $( \pm 3)$ in the variables.

\section{Tests used in this study are:-Physical tests:- ]2[}

(1) Plank Test, to Muscle Strength

(2) $28 \mathrm{~m}$ sprint test, to measure speed.

(3) $28 \mathrm{~m}$ sprint dribbling test, to measure dribble speed.

(4) Nelson test, Reaction.

(5) $10 \times 5 \mathrm{~m}$ shuttle run test, to speed and agility.

(6) T drill test, agility.

(7) orientation SR test, to Coordination

(8) stork stand test, to Balance

(9) s- sit and reach test, to calf muscle flexibility

Shooting tests:-]1[

(1) Two-point shooting test, to shooting accuracy.

(2) Two-point jump shooting test, to shooting accuracy.

(3) Three-point shooting test, to shooting accuracy. 
Scientific transactions used for the tests:-Believe physical tests:-

The Believe of the physical tests was calculated by calculating the accuracy of the distinction by applying them to two groups of (16) players, From Arabic Sports Club, during the period from 20-7-2019 to 27-7-2019.

Table (4)

Significance of differences between the distinctive and indistinctive groups In physical tests

\begin{tabular}{|c|c|c|c|c|c|c|c|}
\hline \multirow{2}{*}{ variables } & \multirow{2}{*}{$\begin{array}{l}\text { measuring } \\
\text { unit }\end{array}$} & \multicolumn{4}{|c|}{\begin{tabular}{c|c} 
distinctivegroup & Indistinctivegroup \\
$\mathrm{N}=4$ & $\mathrm{~N}=4$
\end{tabular}} & \multirow{2}{*}{$\begin{array}{l}\text { Means } \\
\text { difference }\end{array}$} & \multirow{2}{*}{$\begin{array}{l}\text { Calculated } \\
\text { 'T' value }\end{array}$} \\
\hline & & mean & s.d & mean & s.d & & \\
\hline $\begin{array}{l}\text { Plank MuscleStrength } \\
\text { Test }\end{array}$ & Sec & 40.534 & 3.351 & 33.109 & 4.431 & 7.425 & $2.673 *$ \\
\hline 28m sprint test & Sec & 5.365 & 0.326 & 5.904 & 0.231 & 0.539 & $2.698^{*}$ \\
\hline $\begin{array}{l}28 \text { m sprint dribbling } \\
\text { test }\end{array}$ & Sec & 6.145 & 0.319 & 6.801 & 0.332 & 0.656 & $2.849 *$ \\
\hline Nelson Reaction test & Sec & 2.109 & 0.219 & 2.654 & 0.338 & 0.545 & $2.706^{*}$ \\
\hline $10 \times 5 m$ shuttle runtest & Sec & 7.326 & 0.315 & 8.113 & 0.401 & 0.787 & 3.086* \\
\hline T dril test & Sec & 9.795 & 0.464 & 10.737 & 0.505 & 0.942 & $2.747^{*}$ \\
\hline orientation SR test & point & 16.703 & 2.176 & 11.216 & 2.600 & 5.487 & 3.236* \\
\hline stork stand test & Sec & 42.735 & 5.781 & 51.441 & 6.014 & 8.706 & $2.995 *$ \\
\hline s- sit and reach test & C.m & $\mathbf{1 0 . 5 2 1}$ & 2.516 & 4.327 & 1.897 & 6.194 & 3.931* \\
\hline
\end{tabular}

The value of "T" Driven at the level $(0.05)=(2.447)$

Seen from the table (4) and statistically significant differencebetween

distinctive and indistinctive groups differences in physical tests. 
Table (5)

Significance of differences between the distinctive and indistinctive groups In shooting tests

\begin{tabular}{|c|c|c|c|c|c|c|c|}
\hline \multirow{2}{*}{ Variables } & \multirow{2}{*}{$\begin{array}{l}\text { measuring } \\
\text { unit }\end{array}$} & \multicolumn{4}{|c|}{ distinctivegroup Indistinctivegroup } & \multirow{2}{*}{$\begin{array}{l}\text { Means } \\
\text { difference }\end{array}$} & \multirow{2}{*}{$\begin{array}{l}\text { Calculated } \\
\text { 'T' value }\end{array}$} \\
\hline & & mean & s.d & mean & s.d & & \\
\hline $\begin{array}{l}\text { Two-point shooting } \\
\text { test }\end{array}$ & point & 5.250 & 0.829 & 3.500 & $\begin{array}{c}0.500 \\
\end{array}$ & 1.750 & 3.615* \\
\hline $\begin{array}{l}\text { Two-point jump } \\
\text { shooting test }\end{array}$ & point & 5.000 & 0.866 & 3.50 & 0.829 & 1.500 & $2.502 *$ \\
\hline $\begin{array}{l}\text { Three-pointshooting } \\
\text { test }\end{array}$ & point & 4.250 & 0.707 & 2.500 & 0.500 & 1.750 & $4.041^{*}$ \\
\hline
\end{tabular}

The value of " $T$ " Driven at the level $(0.05)=(2.447)$

Seen from the table (5) and statistically significant difference between distinctive and indistinctive groups differences shooting tests.

The stability of physical tests:-

Has been found stability of tests using test method application and reapply coefficient (test-retest) on a sample (16)players, From Arabic Sports Club, He re-applied the tests under the same conditions and the same instructions after (7) days.

Table (6)

Reliability coefficient of physical tests

$\mathrm{N}=16$

\begin{tabular}{|c|c|c|c|c|c|c|c|}
\hline \multirow[t]{2}{*}{ variables } & \multirow[t]{2}{*}{$\begin{array}{l}\text { measuring } \\
\text { unit }\end{array}$} & \multicolumn{2}{|c|}{$\begin{array}{l}\text { Mplementation } \\
\text { first }\end{array}$} & \multicolumn{2}{|c|}{$\begin{array}{l}\text { Mplementation } \\
\text { second }\end{array}$} & \multirow[t]{2}{*}{$\begin{array}{l}\text { Means } \\
\text { difference }\end{array}$} & \multirow[t]{2}{*}{$\begin{array}{l}\text { Calculated } \\
\text { 'T' value }\end{array}$} \\
\hline & & mean & S.d & mean & s.d & & \\
\hline $\begin{array}{l}\text { Plank MuscleStrength } \\
\text { Test }\end{array}$ & Sec & 36.821 & 6.431 & 36.952 & 6.435 & 0.131 & 0.057 \\
\hline 28m sprint test & Sec & 5.624 & 0.513 & 5.590 & $\mathbf{0 . 5 2 3}$ & 0.034 & 0.063 \\
\hline $\begin{array}{l}28 \text { m sprint dribbling } \\
\text { test }\end{array}$ & Sec & 6.473 & 0.622 & 6.481 & 0.613 & 0.008 & 0.040 \\
\hline Nelson Reaction test & Sec & 2.381 & 0.417 & 2.354 & 0.415 & 0.027 & 0.183 \\
\hline $10 \times 5 m$ shuttle runtest & Sec & 7.719 & 0.633 & 7.691 & 0.629 & 0.028 & 0.125 \\
\hline T drill test & Sec & 10.166 & 0.811 & 10.054 & 0.814 & 0.112 & 0.389 \\
\hline orientation SR test & point & 13.959 & 3.404 & 13.875 & 3.401 & 0.084 & 0.069 \\
\hline stork stand test & Sec & 47.088 & 7.118 & 48.002 & 7.215 & 0.914 & 0.359 \\
\hline s- sit and reach test & C.m & 7.424 & 3.217 & 7.514 & 3.213 & 0.090 & 0.082 \\
\hline
\end{tabular}

The value of "T" Driven at the level $(0.05)=(2.131)$ 
Seen from the table (6) there were no statistically significant differences between the first and second two implementations in physical tests demonstrating the enjoyment of these tests transactions high firming.

Table (7)

Reliability coefficient of shooting tests

$\mathrm{N}=16$

\begin{tabular}{|c|c|c|c|c|c|c|c|}
\hline \multirow[t]{2}{*}{ variables } & \multirow[t]{2}{*}{$\begin{array}{l}\text { measuring } \\
\text { unit }\end{array}$} & \multicolumn{2}{|c|}{$\begin{array}{l}\text { Mplementation } \\
\text { first }\end{array}$} & \multicolumn{2}{|c|}{$\begin{array}{l}\text { Mplementation } \\
\text { second }\end{array}$} & \multirow[t]{2}{*}{$\begin{array}{l}\text { Means } \\
\text { difference }\end{array}$} & \multirow[t]{2}{*}{$\begin{array}{l}\text { Calculated } \\
\text { 'T' value }\end{array}$} \\
\hline & & \begin{tabular}{|l|} 
mean \\
\end{tabular} & S.d & mean & s.d & & \\
\hline $\begin{array}{l}\text { Two-point shooting } \\
\text { test }\end{array}$ & point & 4.375 & 1.218 & 4.500 & 1.000 & 0.125 & 0.317 \\
\hline $\begin{array}{l}\text { Two-point jump } \\
\text { shooting test }\end{array}$ & point & 4.250 & 1.165 & 4.000 & 1.1180 & 0.250 & 0.643 \\
\hline $\begin{array}{l}\text { Three-point } \\
\text { shooting test }\end{array}$ & point & 3.375 & 1.218 & 3.500 & 1.118 & 0.1250 & 0.302 \\
\hline
\end{tabular}

The value of "T" Driven at the level $(0.05)=(2.131)$

Seen from the table (7) there were no statistically significant differences

between the first and second two implementations in shooting tests demonstrating the enjoyment of these tests transactions high firming.

\section{Training Program:-}

The training program is designed beside the rest of the other physical elements of the game of basketball through: -

(1) The suggested Footwork Training program has been applied fortwo months during the preparation period of the training season, i.e. (8) weeks; (3) sessions per week.

(2) The training session lasts from 84-93 mines. so that the total timeof the program would be 2160 mines.

(3) The program included (18) exercises for each of the speed, agility, and Polymeric training (Supplement 1).

(4) Application of the training program in Basketball courts has beencarried out in Yarmouk club, Kuwait. 
(5) training method was used high intensity interval training method, with an intensity ranging between (75\% - 90\%) so that the loads used in the program are the medium load, sub maximum load, and maximum load; the weekly Undulating load used is (1:1), (1:2).

(6) Warming up time was determined as (10 mines) and cool down time as (5 mines).

(7) General warm-up exercises to prepare different muscles of thebody to activate the blood circulation, Develop flexibility of the body joints with muscle lengthening.

(8) Skills required to be developed and improved in the technical preparation were distributed, in addition to what was taught from the tactics (individual - groups- teams) in the tactical preparation fitting with the age stage (15) years.

\section{the formation of the load Degree through the stages of the program: -}

- The researcher used the way wavy in the formation of the monthly load (11). (2:1) during load degree from the first week until the 8 week.

- Use the pulse researcher as an indicator for the legalization of contraception and point to guide and evaluate the load and speed ofperformance and rest periods and the number of repetitions.

\section{Before measurements:-}

he researcher conducting tribal measurement and the experimental finding homogeneity the variables on Thursday 1/8/2019 to me Friday 2- 8-2019.

- Thursday $1 / 8 / 2019$ : physical tests

- Friday 2-8-2019 : shooting tests 
Implementation of the basic experience:-

The researcher from the application of the training program on Sunday, from Sunday 4-8-2019 to Friday 4-10-2019, the program was implemented on (Sunday - Monday - Friday)

\section{After measurements:-}

the researcher conducting the After measurements on Sunday 6-10-2019, to me Monday 7-10-2019, under the same conditions that were conducted in the before measurements.

\section{Statistical Analysis:-}

IBM SPSS (17) version was used to conduct statistical processing for the research:

- Mean.

- STD Deviation.

- Skew.

- Calculated 'T' value.

- Improvement Ascriptions. 
Presentation and discussion of the results:-

Table (8)

Significance of differences between the mean of two measurements

(Before - after) In physical tests

$$
\mathbf{N}=17
$$

\begin{tabular}{|c|c|c|c|c|c|c|c|c|}
\hline \multirow[b]{2}{*}{ variables } & \multirow[b]{2}{*}{$\begin{array}{l}\text { measuring } \\
\text { unit }\end{array}$} & \multicolumn{2}{|l|}{ Before } & \multicolumn{2}{|c|}{ after } & \multirow{2}{*}{$\begin{array}{l}\text { Means } \\
\text { difference }\end{array}$} & \multirow{2}{*}{$\begin{array}{c}\text { Improvement } \\
\text { Ascriptions } \\
\%\end{array}$} & \multirow{2}{*}{$\begin{array}{l}\text { Calculated } \\
\text { ' } \mathbf{T} \text { ' value }\end{array}$} \\
\hline & & mean & S.d & mean & s.d & & & \\
\hline $\begin{array}{l}\text { Plank Muscle } \\
\text { Strength Test }\end{array}$ & Sec & 37.254 & 6.542 & 61.504 & 3.251 & 24.250 & 65.093 & $6.115 *$ \\
\hline $28 m$ sprint test & Sec & 5.791 & 0.315 & 5.215 & 0.216 & 0.576 & 9.946 & $4.323 *$ \\
\hline $\begin{array}{l}28 \text { m sprint } \\
\text { dribbling test }\end{array}$ & Sec & 6.564 & 0.473 & 6.014 & 0.289 & 0.550 & 8.379 & $3.885 *$ \\
\hline $\begin{array}{l}\text { Nelson Reaction } \\
\text { test }\end{array}$ & Sec & 2.436 & 0.214 & 2.019 & 0.165 & 0.417 & 17.118 & $4.809 *$ \\
\hline $\begin{array}{l}10 \times 5 m \text { shuttlerun } \\
\text { test }\end{array}$ & Sec & 7.994 & 0.498 & 7.215 & 0.309 & 0.779 & 9.744 & 4.205* \\
\hline T drill test & Sec & 10.143 & 0.803 & 9.357 & 0.547 & 0.786 & 7.749 & $3.516 *$ \\
\hline orientation SRtest & point & 14.903 & 3.265 & 19.428 & 3.151 & 4.525 & 30.363 & $5.903 *$ \\
\hline stork stand test & Sec & 45.092 & 7.434 & 57.281 & 5.490 & 12.189 & 27.031 & $5.427 *$ \\
\hline s- sit and reachtest & C.m & 6.524 & 3.092 & 11.091 & 2.165 & 4.567 & 70.003 & $6.436 *$ \\
\hline
\end{tabular}

The value of " $P$ " Driven at the level $(\mathbf{0 . 0 5})=\mathbf{( 2 . 1 2 0 )}$

Seen from the table there are significant differences where the value of $(\mathrm{t})$

calculated higher than the values of (T) Driven at the level of significance (0.05). 
Table (9)

Significance of differences between the mean of two measurements

(Before - after) In shooting tests

$\mathbf{N}=17$

\begin{tabular}{|c|c|c|c|c|c|c|c|c|}
\hline \multirow[b]{2}{*}{ variables } & \multirow[b]{2}{*}{$\begin{array}{l}\text { measuring } \\
\text { unit }\end{array}$} & \multicolumn{2}{|l|}{ Before } & \multicolumn{2}{|c|}{ After } & \multirow{2}{*}{$\begin{array}{l}\text { Means } \\
\text { difference }\end{array}$} & \multirow{2}{*}{$\begin{array}{c}\text { Improvement } \\
\text { Ascriptions } \\
\%\end{array}$} & \multirow{2}{*}{$\begin{array}{l}\text { Calculated } \\
\text { 'T' value }\end{array}$} \\
\hline & & mean & s.d & mean & s.d & & & \\
\hline $\begin{array}{l}\text { Two-point } \\
\text { shooting test }\end{array}$ & point & 4.546 & 0.471 & 6.315 & 0.316 & 1.769 & 38.913 & 6.901* \\
\hline $\begin{array}{l}\text { Two-point jump } \\
\text { shooting test }\end{array}$ & point & 4.215 & 0.683 & 5.510 & 0.462 & 1.295 & 30.723 & $5.883 *$ \\
\hline $\begin{array}{l}\text { Three-point } \\
\text { shooting test }\end{array}$ & point & 3.200 & 0.554 & 4.658 & 0.501 & 1.458 & 45.562 & $7.215 *$ \\
\hline
\end{tabular}

The value of "P" Driven at the level $(0.05)=(\mathbf{2 . 1 2 0})$

Seen from the table there are significant differences where the value of $(\mathrm{t})$

calculated higher than the values of (T) Driven at the level of significance $(0.05)$.

Researcher discusses the findings of the reality of the research groupand statistical data processors Statistical the Reference and previous studies framework as follows:-

According to the results of the statistical research sample between the tribal and the remote measurement in the physical variables in the table, it is clear from Table (8) that there is a significant difference between the tribal and remote measurements of the experimental group, Table is less than the value of $(t)$ calculated at a significant level (0.05)for the benefit of telemetry indicating that the training program has improved the variables under discussion.

It is clear from the table that the training of the Footwork has been instrumental in the development of the element of measure speed and measure dribble speed, speed and agility, which will generate an involuntary muscle contraction, which works to stimulate other sensory 
organs, thus increasing the number of motor units in the muscles workingon these joints, which are necessary to increase muscle strength.

This is confirmed ]8[ and ]7[ that the training of the Footwork, In another study conducted on the shot, the effect of fatigue on shoot performance was examined. At the level of fatigue created by the $28 \mathrm{~m}$ shuttle running test protocol, it is stated that moderate and high intensity fatigue was a significant effect on the players' shoot performance.

It is known that a Muscle Strength and Reaction are required to shoot. In parallel to this, exercises applied in program consist of rapid Coordination exercises in the study carried out. In other studies on basketball players, the effects of core region training and terabit training on the shooting performance were examined.]9[

The specific basketball training program was significantly improved the physical variable and skill performance of basketball players. ]12[

And also the study showed the possibility to determine the contribution of selected fundamental factors to basketball performance. Therefore, the basketball coach could improve a selected fundamental factor to increase specific basketball ability. This should be addressed in aspecific training to help players to perform successfully in their competitions.]7[

The game of basketball needs sudden burst of speed, unexpected stops, jumps, turns, changes in direction and pace with and without the ball, in response to the direct action of the opponent. 


\section{Conclusions:-}

In light of the nature of this study and the sample and the methodology used and the results of the statistical analysis in the scope of this research researcher reached the following conclusions:-

(1) Training program foot work has the greater impact physical abilities speed, dribble speed, Reaction, agility, Coordination and Balance through the application of the program for a period of (8) week.

(2) Training program foot work has the greater impact in performing shooting through the application of the program for a period of (8) week.

(3) All fundamental skills in basketball namely shooting need a sound foot work to achieve high level performance.

\section{Recommendations:-}

The researcher was able to identify recommendations that benefit thework in the field of training for basketball players is as follows:-

(1) It was concluded from the results of the study, that (8) week basketball specific foot work training protocol is efficient enoughto improve physical ability.

(2) It was concluded from the results of the study, that (8) week basketball specific foot work training protocol is efficient enoughto improve shooting ability.

(3) The specific foot work training is very essential and inter related toselected offensive and defensive skills in basketball. 


\section{Reference:-}

(1) Brenton Boddington : The validity and reliability of the Basketball Jump Shooting Accuracy Test, University of Notre Dame, Australia, 2019.

(2) Garden Tabacchi et al : Field-Based Tests for the Assessment of Physical Fitness in Children and Adolescents Practicing Sport: A Systematic Review within the ESA Program, Journal sustainability, 2019.

(3) Giovanni Fiorilli, Intrieri Mariano, Enzo Iuliano, Arrigo Giombini : Isoinertial Eccentric-Overload Training in Young Soccer Players: Effects on Strength, Sprint, Change of Direction, Agility and Soccer Shooting Precision, Journal of Sports Science and Medicine,2020, 19, 213-223.

(4) Hal Wissel : Basketball Steps to Success (3rd Ed) USA: Human Kinetics, Champign, 2012.

(5) King, Kevin Lee : Effects of an In-season Resistance Training Program on Lower Extremity Power Output in Collegiate Basketball Players, Theses and Dissertations, 2014..p3

(6) Magma : Effects of Ten-day Programmed Training on Specific-Motor Abilities of 15-year-old Basketball Players, Serbian Journal of Sports Sciences, 4 ,2009, 224-228.

(7) Markus James Klusemann: Competition-specific development and preparation of elite basketball athletes, Charles Sturt University, Australia, 2012.

(8) N. PREM KUMAR : Effect of basketball SPECIFIC Footwork Training Protocol on Selected Offensive and DefensiveSkills in basketball, International Journal of Physical Education, Fitness and Sports, ISSN: 2277: 5447 Vol.3.No.2, June'2014 60. 
(9) Seyfi Savaş, Mehmet Fatih Yüksel, Ahmet Uzun : The Effects of Rapid Strength and Shooting Training Applied toProfessional Basketball Players on the Shot Percentage Level, Universal Journal of Educational Research 6(7): 1569-1574, 2018.

(10) S. Lucett : Speed and Agility Training for Basketball, Journal of Strength \& Conditioning Research, 12 ,2013, 212-216.

(11) Umut Canl1 : Effects of Neuromuscular Training on Motoric and Selected Basketball Skills in Pre-pubescent BasketballPlayers, Universal Journal of Educational Research 7(1): 16-23, 2019

(12) Utku Alemdaroğlu : The Relationship Between Muscle Strength, Anaerobic Performance, Agility, Sprint Ability and Vertical Jump Performance in Professional Basketball Players, Journal of Human Kinetics volume 31/2012, 99 - 106 